\title{
Role of Nutrition in Mental Well-Being
}

\section{Kuldip Kumar ${ }^{1}$, Kapil Bansal², Shaily Mina ${ }^{3}$}

\section{IJCRR}

Section: Healthcare

Sci. Journal Impact

Factor: 6.1 (2018)

ICV: 90.90 (2018)
'Professor and Head, Department of Psychiatry, Vardhaman Mahavir Medical College \& Safdarjung Hospital, New Delhi, India; ${ }^{2}$ Post Graduate, Department of Psychiatry, Vardhaman Mahavir Medical College \& Safdarjung Hospital, New Delhi, India; ${ }^{3}$ Associate Professor, Department of Psychiatry, Vardhaman Mahavir Medical College \& Safdarjung Hospital, New Delhi, India.

(ब) $(1)(8$

Copyright@IJCRR

\section{ABSTRACT}

Introduction: A healthy lifestyle plays a pivotal role in maintaining a healthy mind. Dietary balance acts as a major modifiable factor for overall health. Research has shown more risk for metabolic syndrome, cardiac illness, endocrinal disorders, respiratory infections in patients with mental illness (due to medications (an adaptation of an unhealthy lifestyle).

Objective: To highlight the various dietary supplements role in patients suffering from various psychiatric illnesses.

Methods: Various search engines were explored like PubMed, Psyclnfo, ScienceDirect, MEDLINE, Scopus, and GoogleScholar and Cochrane Central Register of Controlled Trials. Result: Various dietary supplements play the role as an augmentation therapy or as the main treatment in milder/initial cases depending upon the state of the psychiatric illness.

Conclusion: We should also emphasize on the maintenance of a healthy lifestyle (regular exercise, diet, sleep) along with the regularity of the treatment. Treating doctor should also attempt to include these dietary supplements in patient's treatment to increase the efficacy of the medication and in turn, decrease the side effects due to the medications.

Key Words: Nutrition, Diet, Lifestyle, Mental health, Psychiatric illness

\section{INTRODUCTION}

Mental health is gradually becoming a major public health issue worldwide. Psychiatric illness attributes to approx. 13\% of the global burden of disease in terms of disability-adjusted life-years (equivalent to cardiovascular and circulatory diseases). ${ }^{1}$ On analysis of the Indian population, almost 200 million people are suffering from a mental disorder, which includes $45 \cdot 7$ million $(42 \cdot 4-49 \cdot 8)$ with depressive disorders and $44 \cdot 9$ million $(41 \cdot 2-48 \cdot 9)$ with anxiety disorders. ${ }^{2}$

It is therefore imperative to deal with this increasing trend of mental disorder otherwise it will hamper peoples overall quality of life, increase mortality and disability due to mental illness and may worsen the underlying/co-morbid medical illness (Alexopoulos GS 2005). Also, mental disorders if not dealt properly can increase the suicide rates, economic loss (absenteeism from work) and disrupts overall family functioning. Also, mental illness increases the chances of much major physical illness- cardiac illness, endocrine disorders, respiratory illness and many more. Therefore, a mental dis- order causes a huge impact on the individual as well as the whole society. ${ }^{3}$

Like the major medical illnesses (hypertension, diabetes, cardiac illness), mental illness also the focus has shifted to preventive measures for the same. Numerous epidemiological studies are going on to elaborate modifiable risk factors for the prevention of mental illness; dietary factors have emerged to be one such significant factor. It has been proposed that different dietary patterns, foods, and nutrients may affect the onset, maintenance, and severity of mental disorders. ${ }^{4}$ Various biological and epidemiological studies have highlighted the role of diet/nutrition in the prevention/ cure of mental disorders but still, the exact mechanism behind it needs a lot of exploration.

The present review attempts to concise the significant findings of the research on the role of nutrition in mental well-being. Also, an attempt has been made to enumerate the role of specific nutrients in specific mental illness for the better understanding of exactly what to be eaten for better mental health ${ }^{5}$.

\section{Corresponding Author:}

Dr. Shaily Mina, Associate Professor, Department of Psychiatry, Vardhaman Mahavir Medical College \& Safdarjung Hospital, New Delhi, India; Phone: 011-26707191; Email: shailymina@gmail.com

ISSN: 2231-2196 (Print)

Received: 22.08 .2020
ISSN: $0975-5241$ (Online)

Revised: 08.10 .2020
Accepted: 10.11 .2020
Published: 07.12.2020 


\section{ROLE OF NUTRITION IN MENTAL HEALTH}

The fat content of our brain is formed by essential fatty acids (omega 3,6); which are majorly provided from outside food which in turn helps in the healthy development of brain neurons. ${ }^{6}$ The diet which we consume on daily bases has been broadly categorized into three types: traditional (vegetables, fruit, beef, lamb, fish, whole-grain foods), western (meat pies, processed meats, pizza, chips, hamburgers, white bread, sugar, flavoured milk drinks, beer), and modern (fruits, salads, fish, tofu, beans, nuts, yoghurt, red wine). ${ }^{7}$

Table 1: Major studies of nutrition and Mental health

\begin{tabular}{|c|c|c|c|}
\hline Psychiatric Illness & Details of Author & Nutrition understudy & Major Highlights \\
\hline \multirow[t]{5}{*}{ DEPRESSION } & Penckofer S et al., 2010 & Vitamin D rich diet & Lower risk of depression \\
\hline & Maurizi CP, 1990 & $\begin{array}{l}\text { Omega } 3 \text { Fatty acid as adjuvant } \\
\text { therapy }\end{array}$ & $\begin{array}{l}\text { Lower risk of depression, Mood } \\
\text { Disorder }\end{array}$ \\
\hline & $\begin{array}{l}\text { Mohandas E and Rajmohan V, } \\
2007\end{array}$ & $\begin{array}{l}\text { Minerals and vitamins (folate, } \\
\text { vitamin } B_{12} \text { ) }\end{array}$ & Lower risk of depression \\
\hline & $\begin{array}{l}\text { Eritsland J, 2000; Stoll AL et al., } \\
1999\end{array}$ & selenium and zinc & Lower risk of depression \\
\hline & Valles-Colomer M et al., 2019 & $\begin{array}{l}\text { Microbiome- Gut-associated } \\
\text { microorganisms (GBMs- Cop- } \\
\text { rococcus, Dialister and Bu- } \\
\text { tyricicoccus }\end{array}$ & $\begin{array}{l}\text { Increases serotonin (via trypto- } \\
\text { phan) }\end{array}$ \\
\hline $\begin{array}{l}\text { BIPOLAR AFFECTIVE } \\
\text { DISORDER }\end{array}$ & Stoll AL, 1999 & omega 3 fatty acids & $\begin{array}{l}\text { better in other areas- cognition, } \\
\text { social and occupational fronts }\end{array}$ \\
\hline $\begin{array}{l}\text { SCHIZOPHRENIA } \\
\text { SPECTRUM DISORDER }\end{array}$ & Aucoin M et al., 2018 & $\begin{array}{l}\text { poor dietary habits use of } \\
\text { refined carbohydrates and fat; } \\
\text { low fibrous diet, omega- } 3 \text { and } \\
\text { omega- } 6 \text { fatty acids, vegetables, } \\
\text { fruit, and certain vitamins and } \\
\text { minerals (vitamin B12 and B6, } \\
\text { folate, vitamin C, zinc, and } \\
\text { selenium) }\end{array}$ & $\begin{array}{l}\text { Increases chances of metabolic } \\
\text { syndrome with medications }\end{array}$ \\
\hline $\begin{array}{l}\text { DEVELOPMENTAL } \\
\text { DISORDER }\end{array}$ & Humphries K et al., 2004 & Poor Nutrition & Secondary Learning disability \\
\hline EATING STORE & Hilbert A et al., 2017 & Poor Nutrition & Lower response to treatment \\
\hline $\begin{array}{l}\text { ATTENTION DEFICIT } \\
\text { HYPERACTIVITY DIS- } \\
\text { ORDER (ADHD) }\end{array}$ & Sinn N, 2008 & $\begin{array}{l}\text { Low levels of iron, zinc, and } \\
\text { magnesium }\end{array}$ & High risk of ADHD \\
\hline ADDICTION & Cook CC, 1998 & $\begin{array}{l}\text { Malnutrition (deficiency of cer- } \\
\text { tain vitamins and minerals) }\end{array}$ & $\begin{array}{l}\text { increase chances of anaemia, } \\
\text { neurological complications (cogni- } \\
\text { tive dysfunction, night blindness, } \\
\text { Wernicke's encephalopathy, and } \\
\text { Korsakoff's Psychosis in alcoholic } \\
\text { patients }\end{array}$ \\
\hline COGNITIVE DECLINE & Valls-Pedret C et. al 2012; 2015 & $\begin{array}{l}\text { poor glucose-regulation; poly- } \\
\text { phenols and Mediterranean diet } \\
\text { supplements with olive oil and } \\
\text { nuts }\end{array}$ & $\begin{array}{l}\text { Cognitive decline in both younger } \\
\text { and older individuals }\end{array}$ \\
\hline
\end{tabular}




\section{Depression}

Research have linked obesity, depression and dietary factors with more depressive symptomatology in individuals with faulty dietary habits and being overweight. It has also been observed that females consuming vitamin D rich food items were at lower risk for depression. ${ }^{7}$ Research also signifies the role of omega-3 as an effective adjunctive therapy for major depressive disorder. ${ }^{8}$ Various studies have supported this observation, and have identified omega 3 fatty acid as one of the contributing factors in the causation of mood disorders as consistently lower levels of this compound is observed in these groups. ${ }^{9}$ It also helps in improving inflammation, therefore, might be beneficial in neurotransmitter generation. ${ }^{10} \mathrm{~A}$ low-fat diet has shown to have mood deprivation properties; altered dietary fat intake can lead to decreased concentration and low energy levels, high protein intake increases alertness. Minerals and vitamins (folate, vitamin B12) also play a pivotal role in causation and improvement of depression. ${ }^{11}$ Folate deficiency can lead to various neuropsychiatric manifestations of which depression is most common. ${ }^{12}$ Almost $25 \%$ of lower levels are observed in depressed individuals in comparison to their healthy counterpart. The study has also attempted to compare the level of improvement with and without the inclusion of folate along with SSRIs and observed greater improvement with the combination. ${ }^{13}$

Low levels of selenium and zinc have been linked with depressed mood. ${ }^{14}$ Trial of oral zinc as an adjunctive treatment has also been tried and found to improve the effectiveness of antidepressants. ${ }^{15}$ Studies have also noted that diet containing sugar, starch (refined), saturated/trans fatty acids, low anti-oxidants and fibrous foods may increase the prevalence of depression. ${ }^{16,17}$ Though these findings are still preliminary, there is no harm in incorporating dietary advice regularly with the ongoing treatment for depression. ${ }^{18,19}$ Research in areas of psychoneuroimmunology and chemical pathways is indicative of a link between nutrition, healthy immune system and smooth functioning of the central nervous system which in turn is responsible for the psychological wellbeing of an individual. ${ }^{20}$ Researches have started identifying diet and nutrition as an important preventive factor for mental disorders. ${ }^{21}$

Forgetfulness is a major concern in much psychiatric illness, it can be improved by memory enhancing foods like- berries (contains flavonoids) ${ }^{22}$; nuts (omega-3 fatty acid called alpha-linolenic acid). ${ }^{23}$ Caffeine also enhances memory by increasing concentration and attentiveness. ${ }^{24}$

Healthy mental health strongly influences our physical health also. Studies have found a positive correlation between the two. Depression and other mental illness can worsen or leads to various medical illnesses like sleep disturbances, cardiovascular disease, gastrointestinal disease, diabetes (due to metabolic syndrome) and fatigability. As famously known-
"Let food be thy Medicine-Hippocrates". When mental health imbalance occurs as in depression, anxiety disorders etc., doing something about it as early as possible can improve overall Quality of Life (QoL). Microbiome population study found a link between microbiome variations in the gut with worsening of overall QOL, a significant indicator for depression. Gut-associated microorganisms (GBMs- Coprococcus, Dialister and Butyricicoccus have been linked to the formation of dopamine metabolites and in turn with QOL and depression. It is also observed that levels of these microorganism changes with and without antidepressant treatment with depleted levels in treatment-free depression. Various microbial pathways are common pathways for depression also, including GABA and tryptophan metabolism, indicating the probability of host-microbe symbiosis. ${ }^{25,26}$ Sources rich in tryptophan (which in turn increases serotonin levels in the brain) like flaxseeds, lentils, bananas, nuts, turkey, yoghurt, milk; if non-vegetarian, fish, eggs and milk have some role in increasing these GBMs in the body..$^{27-29}$

\section{Bipolar Affective Disorders}

Study on bipolar patients has shown a link between omega 3 fatty acids and improvement in the overall course of the illness. Studies comparing the response of omega 3 fatty acids, mood stabilizer (lithium carbonate/valproate) and placebo (olive oil) found longer remission rates in patients on omega 3 fatty acids than the placebo group. Omega 3 fatty acid group also performed better in other areas- cognition, social and occupational fronts. ${ }^{28,29}$

\section{Schizophrenia Spectrum Disorder(includes psychosis)}

Nutrition plays a vital role in patients with psychosis to improve overall health and to curtail the side effects of antipsychotic medication like metabolic syndrome. Observational studies have linked poor dietary habits use of refined carbohydrates and fat; low fibrous diet, omega- 3 and omega- 6 fatty acids, vegetables, fruit, and certain vitamins and minerals (vitamin B12 and B6, folate, vitamin C, zinc, and selenium). ${ }^{30,31}$ Studies have observed that patients suffering from psychosis have faulty eating patterns and lack organization of proper meals $\mathrm{s}^{32}$ in like- major meals in evening with skipping morning meals, eating hastily ${ }^{33,34}$, preferences for junk foods.

Research has observed significantly high levels of glycosylated haemoglobin and insulin, increased waist circumference and diastolic blood pressure in individuals with schizophrenia in comparison to their healthy counterpart. Therefore, these findings support the significance of healthy dietary pattern and physical wellbeing to be equally contributable as a part of the treatment in individuals with schizophrenia in turn decreasing the overall burden of the disease. ${ }^{36,37}$ 


\section{Developmental Disorders}

In regards to Developmental/Intellectual disorders, it was found in systematic nutrition review that poor nutrition (e.g. anaemia) in itself is considered as a risk factor for causation of secondary learning problems further affecting the existing illness. ${ }^{38-40}$

\section{Eating Disorders}

Right knowledge regarding the nutrition values of a particular item aids in better therapeutic response in individuals with eating disorders. Nutrition therapy plays a significant role along with the pharmacological therapy in these individuals. ${ }^{41-43}$

\section{Attention Deficit Hyperactivity Disorder}

Low levels of iron, zinc, and magnesium have shown to worsen the hyperactivity and concentration/ attention problems in children with ADHD. The strongest evidence of nutrition role so far is of omega-3 polyunsaturated fatty acids (PUFA). ${ }^{44-46}$

\section{Addiction}

Nutrition has a role in addiction disorders, specifically alcohol dependence syndrome. Patients with alcohol dependence commonly present with malnutrition (protein-calorie malnutrition) which in turn is a predictor of survival rate in comorbid alcohol liver disease (ALD). Also, deficiency of various vitamins and minerals contributes to the malnutrition- folate, thiamine, pyridoxine, and vitamin A, in turn, increasing the chances of anaemia, neurological complications (cognitive dysfunction, night blindness, Wernicke's encephalopathy, and Korsakoff's Psychosis). ${ }^{47-49}$

\section{Cognitive decline/Dementia/Aging}

Nutrition deficiency can contribute to or worsen cognitive dysfunction. Vascular impairments caused by faulty diet are commonly associated with Alzheimer's and other dementias. It has also been observed poor glucose-regulation to be responsible for cognitive problems even in younger population ${ }^{50-51}$ Nutrition not only plays role in old age, but a healthy diet also reduces future risk of cognitive decline in an adult. There has also been some research highlighting the role of polyphenols and Mediterranean diet supplements with olive oil and nuts in improving cognitive functioning in adult and older population. ${ }^{52}$

\section{DISCUSSION}

The exact mechanism how nutrition plays a therapeutic/preventive measure is still not clear, but it has been proposed that nutrients and their metabolites are consumed in higher quantity than drugs and tend to bind and affect many tar- gets in multiple organs at a time. Though research is still not conclusive indicative of inclusion of following food items in routine diet might decrease the chance of having depression or decrease the ongoing depression- Green leafy vegetables as kale, spinach; broccoli (contains vitamin $\mathrm{K}$, lutein, folate, and beta carotene); Fatty fish, flaxseeds, avocados, and walnuts (contains omega 3 fatty acids); healthy unsaturated fatty acids (lowers beta-amyloid levels, in turn, improving dementia). Simultaneously individual can adapt various healthy ways to keep their mind and physical health healthy besides a healthy diet- regular exercise/yoga, meditation, anger management. ${ }^{53}$ Studies have observed, "whole foods" (with fruit, vegetables, and fish characteristic of intake) to be associated with lesser chances of psychiatric illness than processed foods (largely represented by processed meat and bread products and high-fat dairy products). ${ }^{54}$

Focus on nutrition as an adjuvant treatment is gradually gaining access in many areas of psychiatric illness. A new research field has also emerged- Nutritional Psychiatry which offers potential in identification of the role of dietary components in mental health, including in psychiatric illness, under what circumstances and dosage these interventions are needed and also their role as preventive and therapeutic measures. ${ }^{55}$

\section{CONCLUSION}

Research done so far acknowledges the role of addition of following nutrition in our diet, including fruits and vegetables, grains, nuts, milk and milk products, animal products with limitation of sugar, white flour products floors(like bread, baked goods, cereals, and pasta), animal fats and processed meats. Studies have also shown the Mediterranean diet to be aiding in preventing mental illness. Healthy diet aids in maintaining both physical and mental wellbeing in form oflower incidences of Diabetes, Hypertension, Cardiovascular Disease, and Stroke. Therefore, a balanced diet decreases major chronic medical conditions, also help patients to deal with the metabolic side effects caused by the majority of the psychotropic medications and also decreases the prevalence of mental disorders. Still, lots of large field trials are needed to learn the exact role of nutrition as a modifiable factor in various mental illnesses. But evidence collected till now strongly suggests enrolling of nutrition therapy in the majority of the mental and medical illnesses. More focus should be given to the emerging field i.e. nutritional psychiatry which focuses or studying the pattern of diet role in mental health. More emphasis should be given to nutraceuticals as mood modifying and cognitive-enhancing agents in both clinical and healthy individuals. 


\section{ACKNOWLEDGEMENTS}

All authors contributed equally to this work.

Authors acknowledge the immense help received from the scholars whose articles are cited and included in references to this manuscript. The authors are also grateful to authors/ editors/publishers of all those articles, journals and books from where the literature for this article has been reviewed and discussed.

\section{Conflict of Interest: None Declared}

\section{Ethical Statement}

Since the work was completed as a review article, no ethical approval was needed or sought.

\section{Funding: None}

\section{Availability of Data and Material}

All educational content and materials were created by the expert panel of all the authors and the relevant materials are available with all the authors.

\section{REFERENCES}

1. Adams P, Lawson S, Sanigorski A. Arachidonic acid to eicosapentaenoic acid ratio in blood correlates positively with clinical symptoms of depression. Lipids 1996; 31(1):157-161.

2. Alexopoulos GS. Depression in the elderly. Lancet 2005; 365:1961-70.

3. Aucoin M, LaChance L, Cooley K. Diet and Psychosis: A Scoping Review. Neuropsychobiology 2018; 10:1-23.

4. Benton D, Haller J, Fordy J. Vitamin Supplementation for 1 Year Improves Mood. Neuropsychobiology 1995; 32(2): 98-105.

5. Beydoun M, Gamaldo A, Beydoun H. Caffeine and Alcohol Intakes and Overall Nutrient Adequacy Are Associated with Longitudinal Cognitive Performance among U.S. Adults. Nutr J 2014; 144(6): 890-901.

6. Bilici M, Yıldırım F, Kandil S. Double-blind, placebo-controlled study of zinc sulfate in the treatment of attention deficit hyperactivity disorder. Prog Neuro-Psychopharmacol Biol Psychiatry 2004; 28(1): 181-190.

7. Bourre J. The role of nutritional factors on the structure and functioning of the brain: an update on dietary requirements. Rev Neurol (Paris) 2004; 160 (8-9):767-92.

8. Bourre J. Effects of nutrients (in food) on the structure and function of the nervous system: update on dietary requirements for brain. Part 1: micronutrients. J Nutr Health Aging 2006; 10(5):377-85.

9. Brhlikova P, Pollock AM, Manners R. Global burden of disease estimates of depression--how reliable is the epidemiological evidence? J R Soc Med 2011; 104:25-34.

10. Brown R, Blum K, Trachtenberg M. Neurodynamics of Relapse Prevention: A Neuronutrient Approach to Outpatient DUI Offenders. J Psychoact Drugs 1990; 22(2): 173-187.

11. Bruinsma K, Taren D. Dieting, Essential Fatty Acid Intake, and Depression. Nutr Rev 2009; 58(4):98-108.

12. Buydens-Branchey L, Branchey M, McMakin D. Polyunsaturated fatty acid status and relapse vulnerability in cocaine addicts. Psychiatry Res 2003; 120(1): 29-35.
13. Chouinard G, Young S, Annable L. A controlled clinical trial of 1-tryptophan in acute mania. Biol Psychiatry 1985; 20(5): 546557.

14. Cook C, Hallwood P, Thomson A. B vitamin deficiency and neuropsychiatric syndromes in alcohol misuse. Alcohol 1998; 33(4): 317-336.

15. Cooper Z, Bailey-Straebler S. Disseminating Evidence-Based Psychological Treatments for Eating Disorders. Curr Psychiatry Rep 2015; 17(3): 12.

16. Coppen A, Bailey J. Enhancement of the antidepressant action of fluoxetine by folic acid: a randomized, placebo controlled trial. J Affect Disord 2000; 60(2): 121-130.

17. Curtis L, Patel K. Nutritional and Environmental Approaches to Preventing and Treating Autism and Attention Deficit Hyperactivity Disorder (ADHD): A Review. J Altern Complement Med 2008; 14(1): 79-85.

18. DeMyer M. Comparison of Macronutrients in the Diets of Psychotic and Normal Children. Arch Gen Psychiatry 1968; 18(5): 584.

19. Devore E, Kang J, Breteler M. Dietary intakes of berries and flavonoids in relation to cognitive decline. Ann Neurol 2012; 72(1): 135-143.

20. Ekvall S, Fugazzi P, Stevens F. Pediatric Nutrition Characteristics in Children with Autism. J Am Diet Assoc 2007; 107(8): 28.

21. Eritsland J. Safety considerations of polyunsaturated fatty acids. The American Journal of Clin Nutr 2000; 71(1): 1975-2015.

22. Grotzkyj-Giorgi M. Nutrition and addiction- can dietary changes assist with recovery? Drugs Alcohol Today 2009; 9(2): 24-28.

23. Halsted C. Nutrition and Alcoholic Liver Disease. Semin Liv Dis. 2004; 24(3): 289-304.

24. Herva A, Laitinen J, Miettunen J. Obesity and depression: results from the longitudinal Northern Finland 1966 Birth Cohort Study. Int J Obes 2005; 30(3): 520-527.

25. Hibbeln J. Fish consumption and major depression. Lancet 1998; 351(9110): 1213.

26. Hilbert A, Hoek H, Schmidt R. Evidence-based clinical guidelines for eating disorders. Curr Opin Psychiatr. 2017; 30(6): 423 437.

27. Hoes M. L-tryptophan in depression and strain. J Orthomol Med 1979; 11(4): 231-242.

28. Humphries K, Traci M, Seekins T. Nutrition and Adults with Intellectual or Developmental Disabilities: Systematic Literature Review Results. Intellect Dev Disabil 2009; 47(3): 163-185.

29. Humphries K, Traci M, Seekins T. A preliminary assessment of the nutrition and food-system environment of adults with intellectual disabilities living in supported arrangements in the community. Ecol Food Nutr 2004; 43(6): 517-532.

30. Jacka FN, Pasco JA, Mykletun Aet.al. Association of western and traditional diets with depression and anxiety in women. Am J Psychiatry 2010; 167:305-311.

31. Khanna P, Chattu VK, Aeri B. Nutritional aspects of depression in adolescents - A systematic review. Int J Prev Med 2019; 10: 42.

32. Lakhan S, Vieira K. Nutritional therapies for mental disorders. Nutr J 2008; 7(2).

33. Lian B, Forsberg S, Fitzpatrick K. Adolescent Anorexia: Guiding Principles and Skills for the Dietetic Support of FamilyBased Treatment. J Acad of Nutr Diet 2019; 119(1): 17-25.

34. Marszalek J, Lodish H. Docosahexaenoic acid, fatty acid-interacting proteins, and neuronal function: Breastmilk and Fish Are Good for You. Annu Rev Cell Dev Bi 2005; 21(1): 633-657.

35. Maurizi C. The therapeutic potential for tryptophan and melatonin: Possible roles in depression, sleep, Alzheimer's disease and abnormal aging. Med Hypotheses 1990; 31(3): 233-242. 
36. Merriman S, Haw C, Kirk J. Risk factors for coronary heart disease among inpatients who have mild intellectual disability and mental illness. J Intellect Disabil Res 2005; 49(5): 309-316.

37. Mohandas E, Rajmohan V. Lithium use in special populations. Indian J Psychiatry 2007; 49(3): 211.

38. Owen L, Corfe B. The role of diet and nutrition on mental health and wellbeing. Proc Nutr Soc 2017; 76:425-6.

39. Ozier A, Henry B. Position of the American Dietetic Association: Nutrition Intervention in the Treatment of Eating Disorders. J Am Diet Assoc. 2011; 111(8): 1236-1241.

40. Peebles R, Lesser A, Park C. Outcomes of an inpatient medical nutritional rehabilitation protocol in children and adolescents with eating disorders. J Eat Disord 2017; 5(1).

41. Penckofer S, Kouba J, Byrn M. Vitamin D and Depression: Where is all the Sunshine? Issues Ment Health Nurs 2010; 31(6): 385-393.

42. Popa T. Nutrition and depression at the forefront of progress. $J$ Med Life. 2012; 5(4): 414-419.

43. Pyke J. Nutrition and the chronic schizophrenic.Canadian Nurse 1979; 75(10): 40-3.

44. Ratliff J, Palmese L, Reutenauer E. The effect of dietary and physical activity pattern on metabolic profile in individuals with schizophrenia: a cross-sectional study. Compr Psychiatry 2012; 53(7): 1028-1033.

45. Richardson A. Omega-3 fatty acids in ADHD and related neurodevelopmental disorders. Int Rev Psychiatry 2006; 18(2): 155172.

46. Rocks T, Pelly F, Wilkinson P. Nutrition Therapy during Initiation of Refeeding in Underweight Children and Adolescent
Inpatients with Anorexia Nervosa: A Systematic Review of the Evidence. J Acad Nutr and Diet 2014; 114(6): 897-907.

47. Roick C, Fritz-Wieacker A, Matschinger H. Health habits of patients with schizophrenia. Soc Psychiatry Psychiatr Epidemiol 2007; 42(4): 268-276.

48. Ruhé H, Mason N, Schene A. Mood is indirectly related to serotonin, norepinephrine and dopamine levels in humans: a metaanalysis of monoamine depletion studies. Mol Psychiatry 2007; 12(4): 331-359.

49. Sarris J, Logan A, Akbaraly T. Nutritional medicine as mainstream in psychiatry. The Lancet Psychiatry 2015; 2(3): 271-274.

50. Sarris J. Nutritional psychiatry: from concept to the clinic. Drugs. 2019; 79, 929-934.

51. SathyanarayanaRao TS, Asha M, Ramesh B. Understanding nutrition, depression and mental illnesses. Indian J Psychiatry 2008; 50(2): 77.

52. Simonelli-Muñoz A, Fortea M, Salorio P. Dietary habits of patients with schizophrenia: A self-reported questionnaire survey. Int J Ment Health Nurs 2012; 21(3): 220-228.

53. Sinclair A, Begg D, Mathai M. Omega 3 fatty acids and the brain: a review of studies in depression. Asia Pac J Clin Nutr 2007; (16): 391-7.

54. Sinn N. Nutritional and dietary influences on attention deficit hyperactivity disorder. Nutr Rev 2008; 66(10): 558-568.

55. Stevens L, Zhang W, Peck L. EFA supplementation in children with inattention, hyperactivity, and other disruptive behaviours. Lipids 2003; 38(10): 1007-1021. 